\title{
Increased Time To Concomitant Drug Peak Blood Concentration
}

National Cancer Institute

\section{Source}

National Cancer Institute. Increased Time To Concomitant Drug Peak Blood

Concentration. NCI Thesaurus. Code C54612.

Increased time following concomitant drug administration at which the peak drug blood concentration occurs. 